\title{
Pensamento Computacional em Sala de Aula: Desafios, Possibilidades e a Formação Docente
}

\author{
Adelito B. Farias ${ }^{1}$, Wilkerson L. Andrade ${ }^{2}$, Rayana A. Alencar ${ }^{3}$ \\ ${ }^{1}$ Laboratório de Sistemas Embarcados e Computação - Universidade Federal de \\ Campina Grande (UFCG) \\ Campina Grande - PB - Brasil \\ ${ }^{2}$ Laboratório de Práticas de Software - SPLab. Universidade Federal de Campina Grande \\ (UFCG) Campina Grande - PB - Brasil.

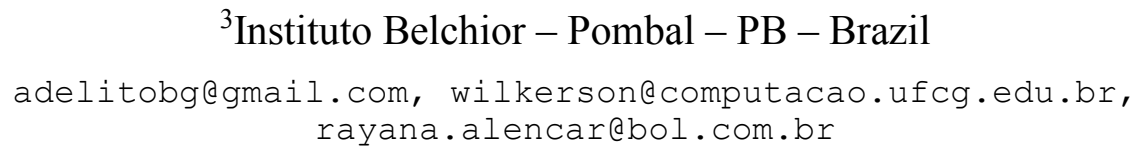

\begin{abstract}
The accelerated and complex transformations in society demanding for a differentiated professional profile, holder of a comprehensive set of skills and competencies aligned to statistical and analytical thinking, which are not limited to advanced manipulation of text editors or spreadsheets, and, in this sense, the computational thinking presents rich subsidies to stimulate and foster such skills and competences. Given this context, this article focuses on the suitability of teacher education to this reality, as well as on the possibilities and the challenges met for the submission of the relevant concepts to the computational thinking in the classroom everyday to the new generations. To assess these scenarios, we applied a questionnaire directed to students graduating from the course of degree in computing, since these are relevant to understanding the degree of science about the importance of Computational Thinking.
\end{abstract}

Resumo. As aceleradas e complexas transformações na sociedade demandam por um perfil profissional diferenciado, detentor de um abrangente conjunto de habilidades e competências alinhadas ao pensamento analítico $e$ estatístico, as quais não se limitam a manipulação avançada de editores de textos ou planilhas eletrônicas, e, neste sentido, o pensamento computacional apresenta subsídios ricos para estimular e fomentar tais habilidades e competências. Considerando este contexto, o presente artigo versa sobre a adequação da formação docente para esta realidade, bem como sobre as possibilidades e os desafios encontrados para a apresentação dos conceitos pertinentes ao pensamento computacional no cotidiano de sala de aula para as novas gerações. Para aferir estes cenários, foi aplicado um questionário direcionado para alunos concluintes do curso de Licenciatura em Computação, visto que estes são oportunos para compreensão do grau de ciência sobre a importância do Pensamento Computacional. 


\section{CBIE-LACLO 2015}

Anais dos Workshops do IV Congresso Brasileiro de Informática na Educação (CBIE 2015)

\section{Introdução}

A Computação, constituída como ciência, não está isolada em técnicas de Engenharia de Software, Métodos Formais ou Modelos Semânticos apenas. Esta ciência está imersa na participação social, corroborando na compreensão de conhecimentos complexos, levando a humanidade para patamares de saber muito mais refinados e superiores do que se dominavam em décadas e séculos passados.

Nossa sociedade presencia os frutos desta ascendente evolução fomentada pelos recursos computacionais, possibilitando a geração de volume de informação gigantesco, no qual tais dados podem subsidiar pesquisas geopolíticas auxiliando na tomada de decisão para o benefício da população (Farias, 2014). Contudo, há muito se questiona se o profissional contemporâneo está habilitado para desempenhar com excelência as funções que a ele são confiadas. Corriqueiramente são encontradas pesquisas e relatos sobre a preocupação da comunidade acadêmica, mais específica a de Computação, sobre as formas de estabelecer perfis técnicos e comportamentais, as práticas de construir e atualizar currículos e ementas e o desenvolvimento e a implantação de metodologias e técnicas de ensino-aprendizagem adequadas (Delgado, 2005).

A comunidade acadêmica está convergindo cada vez mais para a primordial importância da ampliação do ensino de conceitos da Computação, contemplando alunos desde a tenra idade, tornando assim, uma ciência basilar para a formação de habilidades primárias para bom desempenho de qualquer profissão. Exemplos de iniciativas neste cenário são encontrados em alguns estados brasileiros como: Rio de Janeiro (Souza et al., 2014), Minas Gerais (Carvalho et al., 2013), Paraíba (Scaico et al., 2013), Rio Grande do Sul (Andrade et al., 2013), Amazonas (Vieira et al., 2013), Pernambuco (França et al., 2012) e Bahia (Sousa et al., 2010). Neste aspecto, uma aptidão que vem ganhando robustez na aplicação junto aos alunos do ensino fundamental e médio se dá com o Pensamento Computacional.

Corriqueiramente são encontradas várias definições sobre tal estratégia cognitiva. A mais oportuna que mantém consonância com a investigação aqui apresentada, é desenhada por Qin (2009), no qual o pensamento computacional como um arranjo de pensamento que aplica conceitos e metodologias da Computação para solucionar problemas em um amplo espectro de assuntos oferecendo, então, um arcabouço de habilidades essenciais para qualquer ciência contemporânea. Neste aspecto, o Pensamento Computacional seria uma espécie de canivete suíço cognitivo, que analogamente, pertenceria ao kit de sobrevivência intelectual, capaz de ofertar um conjunto de habilidades que potencializa a resolução de problemas complexos e/ou desconhecido aplicando raciocínio computacional. Tamanha é a riqueza educacional do Pensamento Computacional, que variadas publicações estão crescendo nos últimos tempos no cenário internacional, (Barr and Stephenson 2011, Denning 2009, Hu 2011, Wing 2006, Wing 2008), bem como no nacional (França 2014, Gomes 2013, Carvalho 2013, Farias, 2012).

Morin (2001) evidenciou em suas investigações, sete classificações de saberes para serem fomentadores de metodologias educacionais para que estas sejam transdisciplinares, e assim, atender ao futuro da educação em uma perspectiva integral. Enfrentar as incertezas, uma das competências elencadas por Morin (ibid), no qual há uma afirmação favorável, onde ele descreve o futuro como algo ilimitado e 


\section{CBIE-LACLO 2015}

Anais dos Workshops do IV Congresso Brasileiro de Informática na Educação (CBIE 2015)

imprevisível. Isto aporta que há uma quantidade considerável de projetos complexos que nenhum ser humano ainda pensou em esboçar.

Partindo desta necessidade, a presente investigação surgiu da inquietação sobre o brio, a visão diferenciada que os formandos em Licenciatura em Ciência da Computação (LCC) têm para acompanhar atividades de Pensamento Computacional junto aos alunos de formação do Ensino Fundamental e Média. Portanto, este trabalho tem como objetivo delinear a formação docente atual, e para isto, foi realizada uma pesquisa com alunos concluintes do curso de LCC da Universidade Federal Rural de Pernambuco. Acreditase que esta análise contribuirá para que a comunidade acadêmica reflita com mais profundidade sobre a qualidade da formação docente nos cursos de LCC, no tocante ao aparato conceitual que estes futuros profissionais deverão possuir para ter capacidade de fomentar atividades imersas no Pensamento Computacional.

Diante deste cenário, os próximos capítulos abordarão detalhamento desta pesquisa, estruturados da seguinte forma: a Seção 2 aborda a perspectiva dos cursos de Licenciatura no cenário Nacional; a Seção 3 trata da análise dos resultados dos dados coletados; a Seção 4 aborda a reflexão da análise, atenuando as possibilidades bem como os desafios mapeados nesta investigação, e, por conseguinte, os trabalhos futuros que poderão ser acolhidos pela comunidade acadêmica.

\section{Cursos de Licenciatura no Brasil}

As Licenciaturas em Computação têm em sua gênese os objetivos de construir profissionais habilitados para atuar no ensino de Computação e Informática no nível médio e técnico, bem como estarem aptos a atuarem no segmento de mercado que envolve a Informática na Educação de maneira plena (Bezerra 2011). Por um lado mercadológico, não existe uma obrigação formal da introdução de disciplinas de cunho Computacional no Ensino Fundamental e Médio; quando há, são algumas instituições que introduzirem Computação em seus currículos, como matéria de formação, da forma que está adequadamente debatido em Castro (2013).

Nesta perspectiva, diante dos fatos relatados em diversas peças de textos científicos, demonstra que a criação dos cursos de Licenciatura em Computação não possui um mercado bem definido para acolher tais profissionais. Contrapondo este aspecto, Matos (2012) acentua que não é um mero incremento de uma disciplina a mais no currículo escolar. Faz-se necessário a inserção de tal profissional, visto que o conhecimento em Computação já está entranhado na formação cognitiva e social, pelo fato de já pertencer ao cotidiano do cidadão contemporâneo, sendo assim, fundamental a enxertia deste conhecimento, a Computação, como uma disciplina ou transdisciplinar com as demais, cujo êxito decorre da adoção de um profissional de Licenciatura em Computação.

Castro (2013) faz uma observação salutar, ao afirmar categoricamente, que a informática em uma escola, carece de um profissional formado em Licenciatura em Computação, sendo necessário mudança nestes cenários com celeridade. Aqui é válido destacar quão basilar é a formação destes profissionais no tocante ao componente de Pensamento Computacional, uma vez que estes conceitos contribuem para a adoção de um profissional habilitado para lecionar com propriedade os conceitos Computacionais. 
CBIE-LACLO 2015

Anais dos Workshops do IV Congresso Brasileiro de Informática na Educação (CBIE 2015)

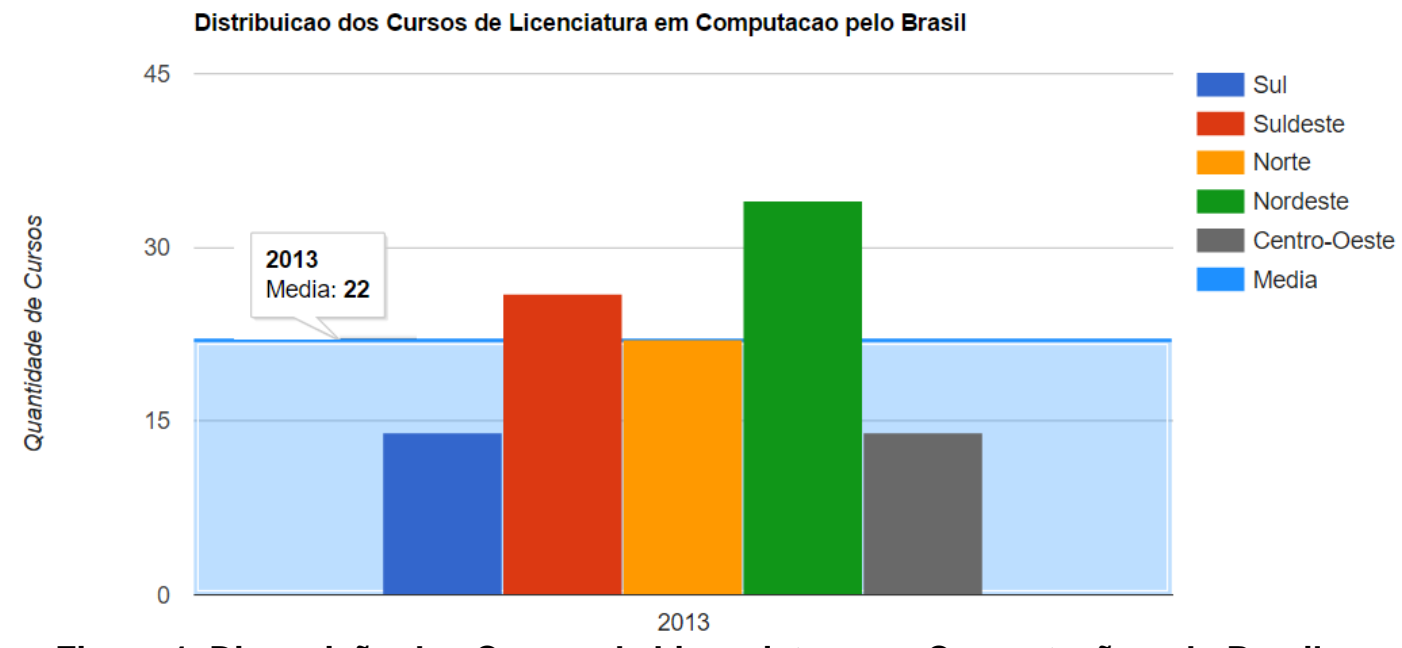

Figura 1. Disposição dos Cursos de Licenciatura em Computação pelo Brasil

Quantitativo evolutivo de cursos de LC no Brasil

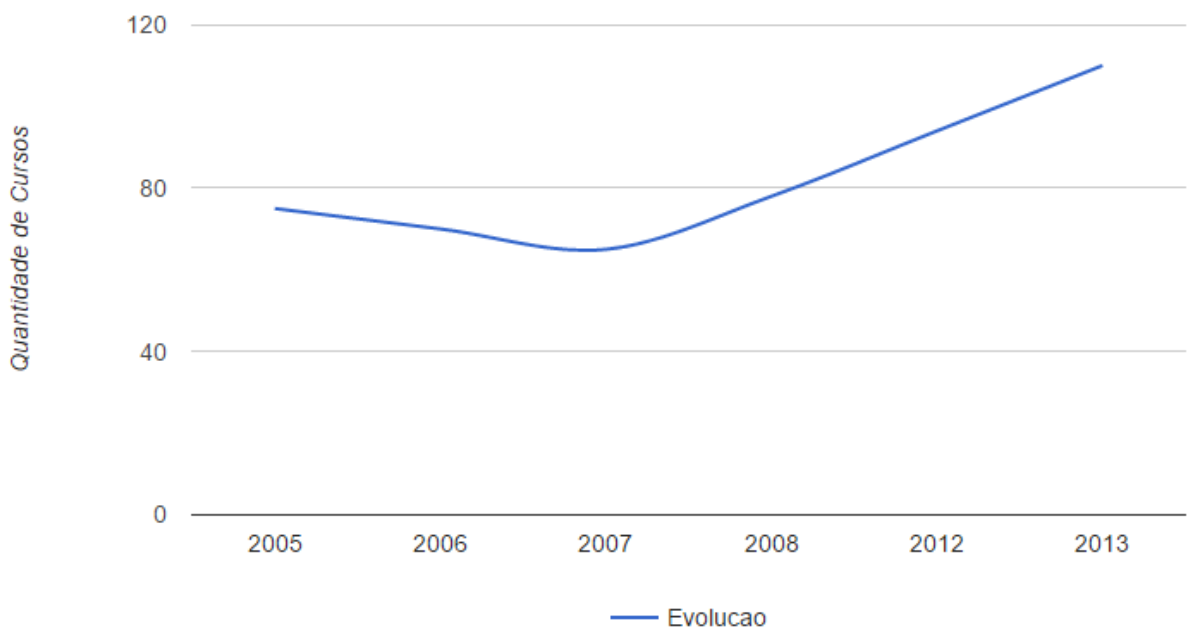

Figura 2. Disposição dos Cursos de Licenciatura em Computação pelo Brasil

Desde o primeiro curso fundado no Brasil, em 1997 na Universidade de Brasília (UnB), muitos outros foram instituídos na nação. Baseado nos dados de Matos (2012) e Castro (2013), todos os estados possuem pelo menos 1 curso, integrando um agrupamento de 68 Instituições com oferta de 110 cursos até o ano de 2013. A Figura 1 expõe o número de cursos por região político-administrativa do Brasil; a Figura 2 demonstra a expansão dos cursos nos últimos anos pelo Brasil. Estes dados corroboram com a crescente necessidade destes profissionais no contexto educacional dos próximos anos. Percebe-se que o Nordeste lidera o ranking na região que mais possui cursos de LCC. 
Com este cenário, foi modelada a crença de que o Licenciando teria uma formação plena, transitando entres nichos dos campos pedagógicos, quanto os tecnológicos, se tornando perito em um destes, mas continuando o vínculo entre os saberes específicos, saberes pedagógicos e tecnológicos (Matos 2012). Entretanto, quais conhecimentos efetivamente estão sendo construídos nestes ambientes acadêmicos? Isto desponta para a necessidade de compreender qual brio que tais egressos estão conquistando para as demandas do cotidiano da sociedade pós-industrial em que vivemos.

\section{Análise dos Resultados}

Como objeto de estudo dessa pesquisa, foram analisadas algumas turmas concluintes do curso de Licenciatura em Computação da modalidade a distância da Universidade Federal Rural de Pernambuco, que cursaram a disciplina optativa de Informática na Educação. Este curso possui carga horária de 2925h, e está distribuído entre os 15 polos nas seguintes cidades do estado de Pernambuco: Afrânio, Gravatá, Limoeiro, Pesqueira, Surubim, Cabrobó, Ipojuca, Olinda, Petrolina, Tabira, Carpina, Jaboatão dos Guararapes, Palmares, Recife e Trindade.

A análise realizada incluiu a coleta e análise de dados realizados a partir das respostas de um questionário aplicado com estes alunos. O questionário abrangeu 13 perguntas que contemplaram o conhecimento do aluno sobre os conceitos que circundam o Pensamento Computacional, a identificação da experiência profissional e as limitações para implantar atividades voltadas para o desenvolvimento deste conceito. As perguntas são detalhadas a seguir:

\section{O conhecimento do aluno sobre os conceitos que circundam o Pensamento Computacional}

1. Você já havia escutado este termo antes, Pensamento Computacional? Se sua resposta for "não", por favor, passe para a questão 4.

2. Se sua resposta foi sim, em qual meio você teve contato com o conceito? Se sua resposta foi sim, em qual lugar teve contato com o conceito?

3. Para você o que significa pensamento computacional na prática?Para você o que significa pensamento computacional?

\section{Identificação da experiência profissional}

4. Você atua como docente em escolas? Se sim por favor passar para a questão 6 e finalizar o questionário.

5. Qual a razão de não estar atuando na docência?

6. Você ministra aulas em escolas públicas ou privadas?

7. Em que níveis de escolaridade você atua?

8. Você apresenta conceitos de pensamento computacional para seus alunos?

9. Se sim, como se dá esta prática?

10. Essas ações foram iniciadas por quem? 
CBIE-LACLO 2015

Anais dos Workshops do IV Congresso Brasileiro de Informática na Educação (CBIE 2015)

\section{Limitações para implantar atividades voltadas para o desenvolvimento desse conceito}

11. Você acredita que apresentar os conceitos de pensamento computacional despertam maior interesse nos alunos?

12. Você enfrenta alguma dificuldade para inserção desses conceitos na sala de aula?

13. Se sua resposta foi sim, o que motiva estas dificuldades?

O questionário tem duas perguntas abertas, desta forma é possível compreender o sentimento do aluno com mais precisão. Elas são as seguintes: (i) para você o que significa pensamento computacional na prática? (ii) você enfrenta alguma dificuldade para inserção desses conceitos na sala de aula? Se sua resposta foi sim, o que motiva estas dificuldades?

\subsection{Coleta dos Dados}

Com o objetivo de fazer o levantamento das informações necessárias para a elaboração desta investigação, foi elaborado um questionário e enviado por email para 30 alunos regularmente matriculados na disciplina de Informática na Educação. Deste total, 16 alunos, espalhados pelos polos do Estado de Pernambuco, responderam ao questionário compreendendo $53,3 \%$ do total pesquisado. A disciplina foi escolhida por fazer parte das disciplinas do penúltimo período do curso. Ressalta-se que o número aparentemente singelo, é de porte significante pelo fato da quantidade de alunos formandos em um curso de Computação ser comumente baixo nas academias federais.

\subsection{Análise dos Dados}

Após a coleta e compilação das respostas do questionário, foram realizadas algumas análises com o objetivo de traçar o perfil dos alunos que estão concluindo o curso superior em Licenciatura em Computação, a adequação do curso e da visão do estudante sobre a compreensão dos conceitos de Pensamento Computacional e as expectativas da aplicação em sala de aula. As subseções a seguir irão detalhar essa análise.

\subsubsection{Análise do Perfil do Aluno Concluinte}

Ficou evidente desde a primeira pergunta que, quase metade dos alunos entrevistados $(43,8 \%)$ conhece o termo "Pensamento Computacional". Porém, os resultados em relação a segunda pergunta revelam que os alunos concluintes não tiveram contato sobre o tema durante a sua vida acadêmica; $42,8 \%$ dos alunos que afirmaram conhecer o termo, disseram que aprenderam através de investigação particular e 28,57\% conheceram o tema através de outros métodos de aprendizagem. Apenas 13,33\% dos alunos relataram ter visto o conceito durante o curso. Essa é uma prova alarmante para um contexto de formação acadêmica dos futuros profissionais, e deve ser analisada com bastante cautela pelas IES (Instituições de Ensino Superior), em uma possível restruturação dos Projetos Políticos-Pedagógicos (PPP).

Em relação aos conceitos sobre Pensamento Computacional (Pergunta 3), 31,2\% dos entrevistados, expuseram suas reflexões e seus depoimentos a seguir, exemplificam quão singela é a disseminação deste conceito entre os alunos concluintes. 


\section{CBIE-LACLO 2015}

Anais dos Workshops do IV Congresso Brasileiro de Informática na Educação (CBIE 2015)

Aluno A: Compreende que Pensamento Computacional é tão simplesmente pensar nas tecnologias contemporâneas com o objetivo de ser inserido na atual dinâmica mercadológica.

Aluno B: Entende que abstrair a realidade por meio de uma interação lógica e objetiva para auxiliar as atividades que são necessárias, se traduz em Pensamento Computacional.

Aluno C: Evolução de todos os sentidos sensoriais e cognitivos caracteriza Pensamento Computacional

Aluno D: Tem a clara função da ferramenta computacional na sociedade, é Pensamento Computacional

Aluno E: Usar a ferramenta computacional para solucionar problemas é compreendido como Pensamento Computacional

Em relação aos alunos que não conhecem o termo "Pensamento Computacional", foi direcionada a pergunta para compreender atuação como docente em escolas (Pergunta 4), 75\% disseram que não estão atuando em escolas. A pergunta 5, busca descobrir o motivo pelo qual os entrevistados não estão em atuação na docência. Foi possível obter as seguintes informações: $31,3 \%$ declarou que atuam em outras áreas por opção, $25 \%$ afirmou que atua em outra área porque não encontrou espaço no mercado como professor, $18,8 \%$ respondeu outros e apenas $6,3 \%$ diz estar desempregado. Aqui nota-se uma necessidade de delinear claramente qual a função de um docente em Licenciatura em Computação, para que as instituições de ensino busquem com mais afinco estes profissionais.

A pergunta 6 só foi respondida pelos entrevistados que já atuam na docência em escolas públicas ou privadas, dos que responderam 12,5\% lecionam em escolas públicas, 6,3\% para escolas privadas e esse mesmo valor para ambas as modalidades, $25 \%$ optaram por outras origens, mas não foi relatado no questionário. A atuação dos entrevistados que responderam essa pergunta no aspecto nível de escolaridade (Pergunta 7) é no Ensino Fundamental II ( $6^{\circ}$ ao $9^{\circ}$ ano) com $18,8 \%$ das respostas, com $31,3 \%$ das respostas para outros níveis e elas não foram explicitadas no questionário. Os entrevistados que atuam na docência também foram questionados sobre a exposição do Pensamento Computacional durante as suas aulas (Pergunta 8). Destes, 57\% (4 entrevistados) afirmam que já apresentaram conceitos de pensamento computacional e $43 \%$ (3 entrevistados) não o fizeram. A pergunta 9 , sonda sobre a prática em relação ao Pensamento Computacional e observando a Figura 3, que relata o resumo das respostas dos entrevistados, percebe-se que $40 \%$ selecionam material didático para auxiliar na compreensão. Por outro lado, apenas $20 \%$ diz usar Software Educacional e $40 \%$ optou por outros, não especificando quais recursos seriam estes.

Acentua-se aqui, quão necessário é o amadurecimento da compreensão sobre o que de fato inviabiliza a prática docente com o pensamento computacional. Aliado com a argumentação de Perris (2013), o desafio não é a utilização de novas tecnologias para reproduzir os sistemas tradicionais de ensino, mas fomentar novos espaços de aprendizagem, proporcionando melhorias para professores e alunos, e, por conseguinte melhorar a qualidade da educação. 
CBIE-LACLO 2015

Anais dos Workshops do IV Congresso Brasileiro de Informática na Educação (CBIE 2015)

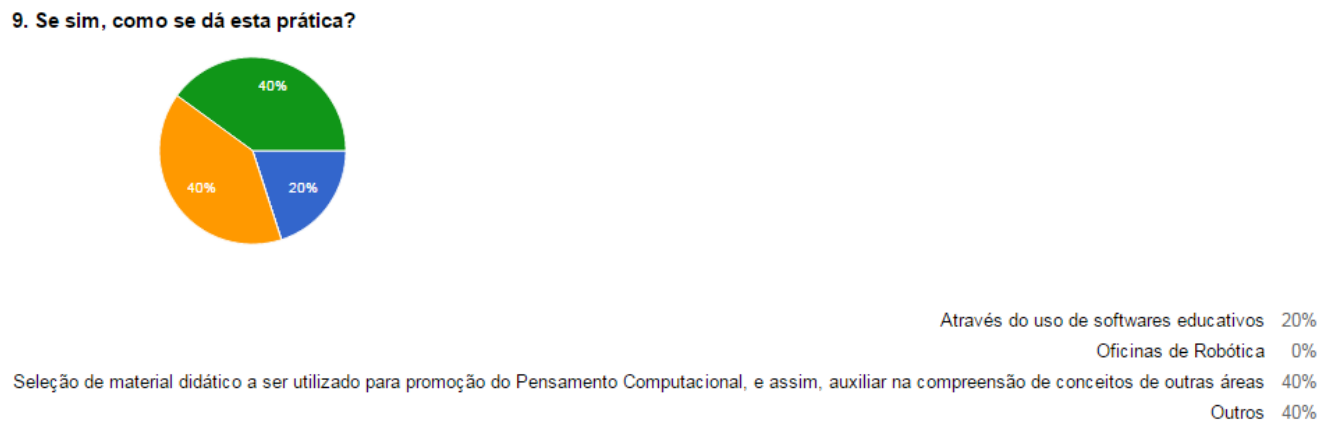

Figura 3. Resumo das respostas da pergunta 9 do questionário

Na pergunta 10, com o objetivo de compreender de quem partiu o estímulo fomentador das atividades de Pensamento Computacional, foi possível compreender que $20 \%$ foram os alunos que solicitaram iniciativas dos docentes; $60 \%$ foram atitudes particulares dos docentes, e 20\% são descritos como outros, não descrevendo quais recursos seriam estes. Quando questionados sobre a relevância no despertar o interesse nos alunos (Pergunta 11), todos foram harmônicos, concordando quanto à eficácia das atividades de Pensamento Computacional. Ao serem questionados se enfrentaram alguma dificuldade para inserção desses conceitos na sala de aula (Pergunta 12), também foram concisos ao afirmarem que não encontraram barreira para aplicar as atividades. Na pergunta 13, não se obteve respostas relevantes para a pesquisa.

\section{Reflexões Conclusivas}

O Governo Federal, diante da necessidade de formar profissionais para atender à indústria, vem fazendo crescentes investimentos na educação técnica, democratizando o acesso à capacitação. Tais políticas educacionais contribuíram para a expansão da oferta de cursos de Licenciatura em Computação, mas a visibilidade ainda não atende às expectativas para o qual os cursos foram projetados. Há necessidade de construir oportunidades para a atuação do profissional e firmar a identidade, bem como a valorização, do curso de LCC para a sociedade brasileira.

Nesta investigação, aspectos que compõe a realidade vivida pelos estudantes concluintes do curso de LCC foram coletados e analisados para averiguar qual o poder de compreensão e formação que estes possuem sobre tópicos de Pensamento Computacional. Notou-se que os estudantes possuem clara limitação conceitual sobre o componente, tendo respostas fundamentadas em crenças, destoando do que de fato a literatura instrui. Existe pouca atividade por parte destes concluintes, na promoção do Pensamento Computacional com estudantes do ensino fundamental e médio.

Esta investigação não tem o propósito de ficar apenas limitada nas falhas metodológicas, culminando no singelo dinamismo na promoção do Pensamento Computacional. Ao observar que as habilidades de uma turma de alunos concluintes estão carentes em seu fundamento basilar, acredita-se que tal cenário não foi estimado quando formularam os cursos de LCC no Brasil. Por tal, fazer uma profunda consideração sobre o que de fato espera-se de um profissional em LCC poderá ser determinante para a propagação do Pensamento Computacional, ou capaz deste marasmo ceifar o potencial cognitivo de uma geração que tende em atingir patamares mais sofisticados que as gerações contemporâneas. 


\section{CBIE-LACLO 2015}

Anais dos Workshops do IV Congresso Brasileiro de Informática na Educação (CBIE 2015)

Como meta futura, pretende-se aprimorar o questionário aplicado nesta investigação, para ser mais abrangente, pois se tem o intuito de coletar mais informações de outros estados do Nordeste, e caso exista viabilidade, cogita-se aplicar em cursos do Brasil. Assim, buscaremos ter um comparativo mais holístico da real formação dos docentes em Licenciatura em Computação no tocante ao Pensamento Computacional.

\section{Referências}

Andrade, D., Carvalho, T., Silveira, J., Cavalheiro, Foss, L., Fleischmann, A. M., Aguiar, M., Reiser, R. (2013). Proposta de Atividades para o Desenvolvimento do Pensamento Computacional no Ensino Fundamental. In: XVI WIE, SBC.

Barr, V.; Stephenson, C. (2011). Bringing Computational Thinking to K-12: What is Involved and What is the Role of the Computer Science Education Community? ACM, Inroads, Vol. 2 - No. 1.

Bezerra, L.N. M.; Silveira, I.F. (2011). Licenciatura em Computação no Estado de São Paulo: uma Análise Contextualizada e um Estudo de Caso. WIE, SBC.

Carvalho, M. L. B.; Chaimowicz, L.; Moro, M.. M. (2013) Pensamento Computacional no Ensino Médio Mineiro. In: pp. 640-649, Anais do XXI WEI, CSBC, SBC.

Castro, CS; Vilarim, GO. (2013) Licenciatura em Computação no cenário nacional: embates, institucionalização e o nascimento de um novo curso. Revista Espaço Acadêmico, no 148.

Delgado, C., Xexéo, J., Souza, I., Rapkiewicz, C., Junior, J. P. (2005). Identificando competências associadas ao aprendizado de leitura e construção de algoritmos. In: XXV CSBC - X WEI.

Denning, P. J. (2009). Beyond Computational Thinking. Communications of the ACM, Vol. 52 No. 6, Pages 28-30.

Farias, A. B. , Xavier, M. P. , Dobroes, J. A. L., Cabral, G. R. E. (2014) Educação em Saúde no Brasil: uma revisão sobre tecnologias móveis e desafios na promoção de saúde. In: XIX Conferência Internacional sobre Informática na Educação.

Farias, A. B.; Henrique, M. ; Cunha, F. O. M. ; Scaico, P. D. (2012). Atividades desplugadas: uma maneira lúdica de ensinar conceitos computacionais. SENID.

França, R. S, Ferreira, V.A.S., Almeida, L.C.F., Amaral, H.J.C.(2014) A disseminação do pensamento computacional na educação básica: lições aprendidas com experiências de licenciandos em computação. CSBC -WEI, SBC.

França, R. S, Silva, W. C., AMARAL, H.J.C. (2012). Ensino de ciência da computação na educação básica: Experiências, desafios e possibilidades. In: XX WEI, SBC.

Gomes, T. C. S., Melo, J. C. B. (2013). O Pensamento Computacional no Ensino Médio: Uma Abordagem Blended Learning. In: XXI WEI, SBC.

$\mathrm{Hu}, \mathrm{C}$. (2011). Computational thinking: what it might mean and what we might do about it. In Procs. of ITiCSE, pages 223-227, Darmstadt, Alemanha.

Matos, E. S., Silva, B. G.F. (2012) Currículo de licenciatura em computação: uma reflexão sobre perfil de formação à luz dos referenciais curriculares da SBC. Anais do XXXII CSBC. Curitiba, PR.

Morin, E. (2001). Os sete Saberes Necessários à Educação do Futuro 3a. ed. - São Paulo Cortez; Brasília, DF: UNESCO. 
Perris, P. A. R., Rodrigues, R. L., Gomes, A. S.(2013) Concepção de ferramentas de percepção, representando dados do fluxo de atividades discentes em ambiente colaborativo de aprendizagem. In: II CBIE - XXIV SBIE.

Qin, H. (2009). Teaching computational thinking through bioinformatics to biology students. In Procs. of SIGCSE, pages 188-191, Chattanooga, TN, EUA.

Scaico, P.D., Lima, A.A., Azevedo, S., Silva, J. B. B., Raposo, E.H., Paiva, L.F., Alencar, Y., Mendes, J.P., Scaico, A. (2013). Ensino de Programação no Ensino Médio: Uma Abordagem Orientada ao Design com a linguagem Scratch. RBIE, v. 21, n. 02, p. 92.

Sousa, R.V., Barreto, L.P., Andrade, A., Abdalla, D. (2010). Ensinando e aprendendo conceitos sobre a ciência da computação sem o uso do computador: Computação Unplugged!. Práticas em Informática na Educação: Minicursos do CBIE, v.1, n.1.

Souza, C.S; Salgado, L.C.C.; Leitão, C.F.; and Serra. M.M. (2014). Cultural appropriation of computational thinking acquisition research: seeding fields of diversity. In: Proc. of the 19th ITiCSE. ACM, 2014. p. 117-122.

Vieira, A., Passos, O., Barreto, R. (2013). Um Relato de Experiência do Uso da Técnica Computação Desplugada. In: Anais do XXI WEI, p. 670-679.

Wing, J. M. (2006). Computational thinking. Communications of the ACM, v. 49, n. 3, p. 3335.

Wing, J. M. (2008). Computational thinking and thinking about computing. Philosophical Transactions of the Royal Society A: Mathematical, Physical and Engineering Sciences, v. 366, n. 1881, p. 3717-3725. 